\title{
Corrigendum
}

\section{Corrigendum to "Analytical Investigation of the Flexural Capacity of Precast Concrete Frames with Hybrid Joints"}

\author{
Ji-Hun Kim, ${ }^{1}$ Won-Kee Hong $\mathbb{D}^{1}{ }^{1}$ Hee-Cheul Kim, ${ }^{1}$ and Seong-Kyum Kim ${ }^{2}$ \\ ${ }^{1}$ Department of Architectural Engineering, Kyung Hee University, Yongin 17104, Republic of Korea \\ ${ }^{2}$ Research Institute for Mega Structures, Korea University, Engineering Building, Seoul 02841, Republic of Korea \\ Correspondence should be addressed to Won-Kee Hong; hongwk@khu.ac.kr \\ Received 17 July 2019; Accepted 8 August 2019; Published 11 April 2020 \\ Copyright (c) 2020 Ji-Hun Kim et al. This is an open access article distributed under the Creative Commons Attribution License, \\ which permits unrestricted use, distribution, and reproduction in any medium, provided the original work is properly cited.
}

In the article titled "Analytical Investigation of the Flexural Capacity of Precast Concrete Frames with Hybrid Joints" [1], an acknowledgment should be added as follows:

\section{Acknowledgments}

"This work was supported by the Basic Science Research Program through the National Research Foundation of Korea (NRF) funded by the Ministry of Education (NRF2016R1D1A1A02937558)."

\section{References}

[1] J.-H. Kim, W.-K. Hong, H.-C. Kim, and S.-K. Kim, “Analytical investigation of the flexural capacity of precast concrete frames with hybrid joints," Advances in Civil Engineering, vol. 2019, Article ID 7470128, p. 12, 2019. 